\title{
Early Implementation of SiC Cladding Fuel Performance Models in BISON
}

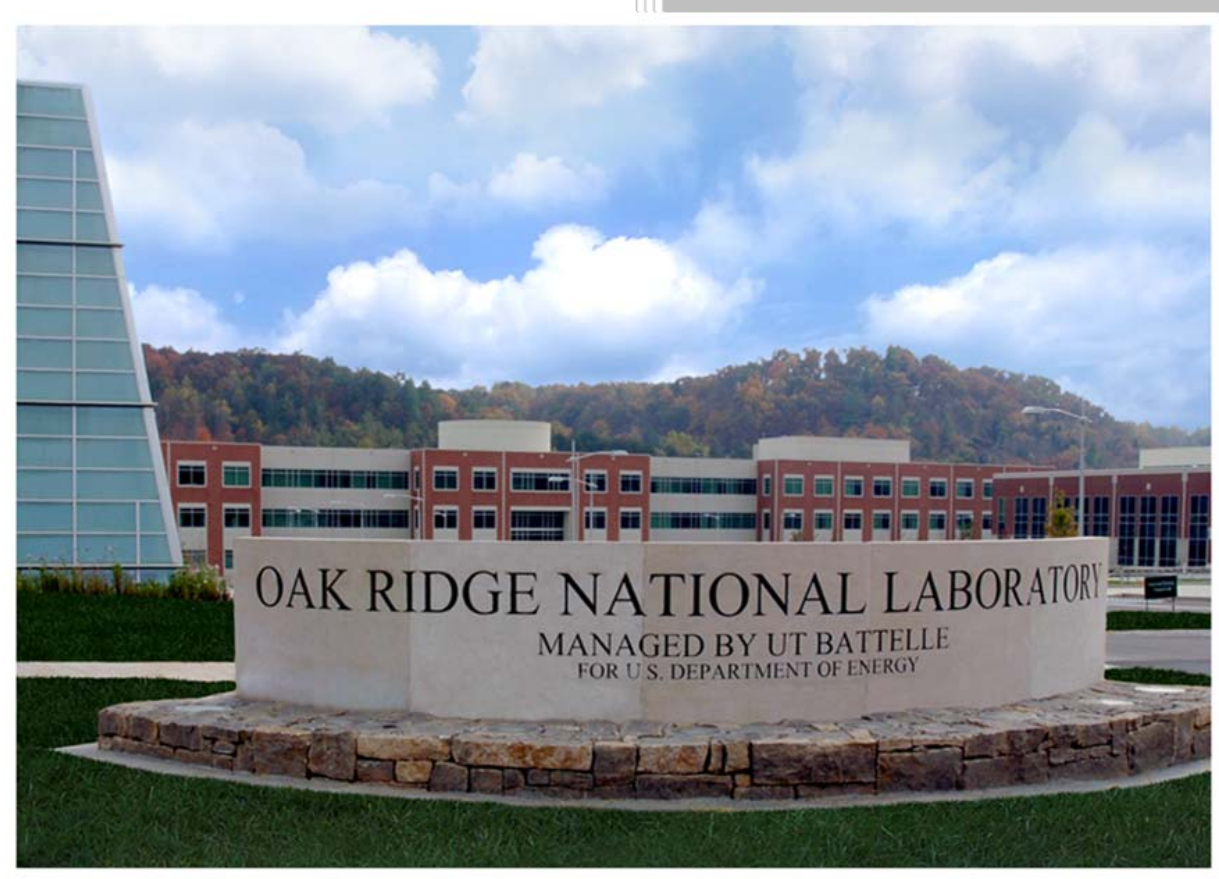

J. J. Powers

Approved for public release. Distribution is unlimited. 


\title{
DOCUMENT AVAILABILITY
}

Reports produced after January 1, 1996, are generally available free via US Department of Energy (DOE) SciTech Connect.

Website http://www.osti.gov/scitech/

Reports produced before January 1, 1996, may be purchased by members of the public from the following source:

\author{
National Technical Information Service \\ 5285 Port Royal Road \\ Springfield, VA 22161 \\ Telephone 703-605-6000 (1-800-553-6847) \\ TDD 703-487-4639 \\ Fax 703-605-6900 \\ E-mail info@ntis.gov \\ Website http://www.ntis.gov/help/ordermethods.aspx
}

Reports are available to DOE employees, DOE contractors, Energy Technology Data Exchange representatives, and International Nuclear Information System representatives from the following source:

Office of Scientific and Technical Information

PO Box 62

Oak Ridge, TN 37831

Telephone 865-576-8401

Fax 865-576-5728

E-mail reports@osti.gov

Website http://www.osti.gov/contact.html

This report was prepared as an account of work sponsored by an agency of the United States Government. Neither the United States Government nor any agency thereof, nor any of their employees, makes any warranty, express or implied, or assumes any legal liability or responsibility for the accuracy, completeness, or usefulness of any information, apparatus, product, or process disclosed, or represents that its use would not infringe privately owned rights. Reference herein to any specific commercial product, process, or service by trade name, trademark, manufacturer, or otherwise, does not necessarily constitute or imply its endorsement, recommendation, or favoring by the United States Government or any agency thereof. The views and opinions of authors expressed herein do not necessarily state or reflect those of the United States Government or any agency thereof. 


\title{
EARLY IMPLEMENTATION OF SIC CLADDING FUEL PERFORMANCE MODELS IN BISON
}

\author{
J. J. Powers
}

Date Published: September 18, 2015

Prepared by OAK RIDGE NATIONAL LABORATORY

Oak Ridge, TN 37831-6283 managed by

UT-BATTELLE, LLC for the US DEPARTMENT OF ENERGY under contract DE-AC05-00OR22725 



\section{CONTENTS}

CONTENTS

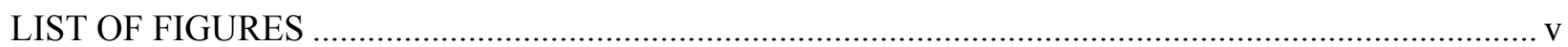

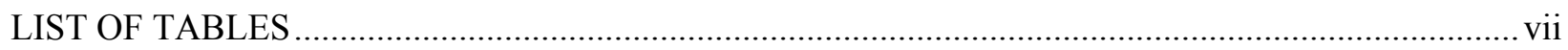

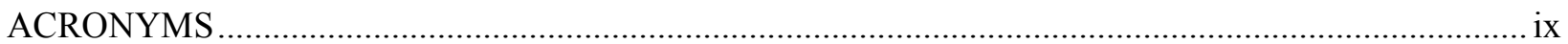

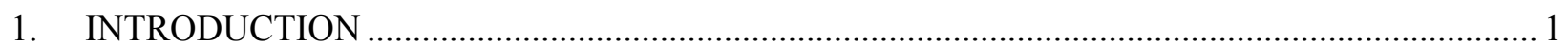

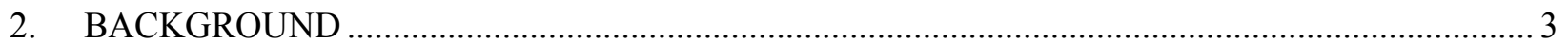

2.1 SILICON CARBIDE DEVELOPMENT PROGRAM …................................................... 3

2.2 NEUTRONIC ASSESSMENT OF SILICON CARBIDE FOR PWR CLADDING ................. 4

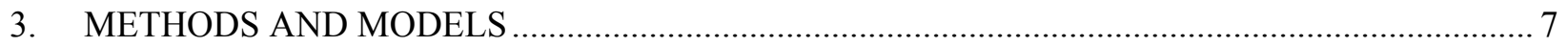

3.1 THERMOMECHANICAL FUEL PERFORMANCE MODELING …................................ 7

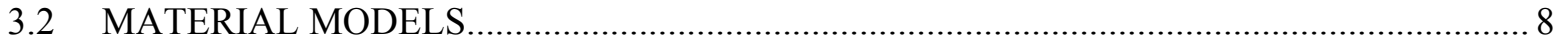

4. SILICON CARBIDE BENCHMARK PROBLEM SPECIFICATION …................................. 9

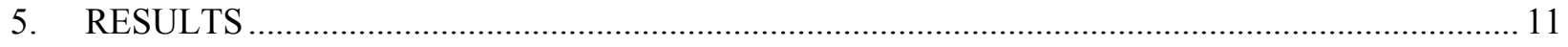

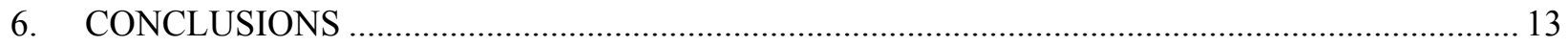

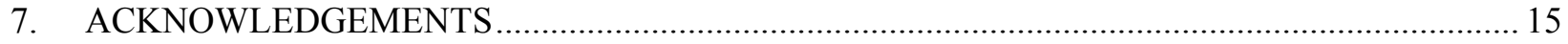

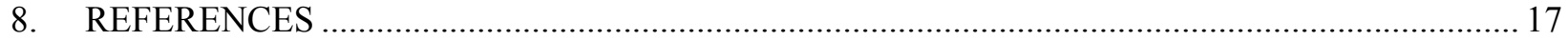

APPENDIX A. REPRESENTATIVE BISON INPUT FILE FOR THE SIC CLADDING

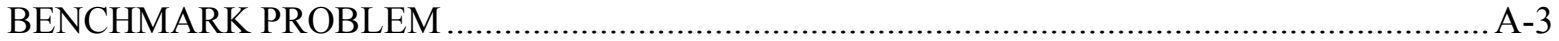




\section{LIST OF FIGURES}

Fig. 1. Fuel parameter combinations that match cycle length of PWR with Zircaloy. [17,19]................ 5

Fig. 2. Illustration summarizing the $\mathrm{SiC}$ benchmark problem geometry and specifications [33]............. 9

Fig. 3. Close-up view of the top of the 2D model for the SiC benchmark problem............................... 11

Fig. 4. Radial (left), axial (center), and hoop (right) stress profiles calculated across the cladding tube at the axial midplane of the benchmark problem using simplified material properties. ........ 11

Fig. 5. Radial stress results near the axial midplane (marked with a white line) of the $\mathrm{SiC}$ cladding benchmark using simplified material properties 


\section{LIST OF TABLES}

Table 1. Summary of relevant data for key cladding material options, adapted from [17] ...................... 4

Table 2. Fuel parameter combinations that match cycle length of PWR with Zircaloy [19] ...................... 5

Table 3. Fuel specifications for ORNL PWR ATF analyses ........................................................... 6 


\section{ACRONYMS}

ATF

BDBA

BWR

CMC

CVD

CVI

DOE-NE

EFPD

FCRD

$\mathrm{FeCrAl}$

FP

$\mathrm{GWd} / \mathrm{tHM}$

$\mathrm{HM}$

HT

INL

JFNK

LWR

LWRS

MOOSE

MW/tHM

NITE

ORNL

PCMI

PWR

$\mathrm{SiC}$

STEP accident-tolerant fuel

beyond design basis accident

boiling water reactor

ceramic matrix composite

chemical vapor disposition

chemical vapor infiltration

US Department of Energy Office of Nuclear Energy

effective full power day

Fuel Cycle Research and Development

ferritic iron-chromium-aluminum

fission product

gigawatt days per ton of heavy metal

heavy metal

high temperature

Idaho National Laboratory

Jacobian-Free Newton Krylov

light water reactor

light water reactor sustainability (a DOE-NE program)

Multiphysics Object-Oriented Software Environment

megawatts per ton of heavy metal

nanoinfiltration and transient eutectic-phase

Oak Ridge National Laboratory

pellet-cladding mechanical interaction

pressurized water reactor

silicon carbide

systematic technology evaluation program 


\section{INTRODUCTION}

The US Department of Energy Office of Nuclear Energy (DOE-NE) Fuel Cycle Research and Development (FCRD) Advanced Fuels Campaign is developing enhanced accident-tolerant fuel (ATF) concepts to replace the standard urania fuel in zirconium alloy cladding $\left(\mathrm{UO}_{2} /\right.$ Zircaloy $)$ system used in existing light water reactors (LWRs) [1-3]. Candidate ATFs should improve performance during beyond design basis accidents (BDBAs) by increasing the amount of time available for mitigation actions, reducing the rate and/or extent of heat and hydrogen production during high-temperature (HT) steam oxidation, and/or reducing severe accident consequences by enhancing fission product (FP) retention. Numerous approaches have been developed to accomplish one or more of these objectives. Two basic pathways involve (1) changing the cladding to enhance performance during severe accidents, and/or (2) changing the fuel to either directly improve performance or overcome obstacles introduced by changing the cladding material. Possible cladding changes include coating the standard Zircaloy cladding with a thin ceramic or metallic layer to decrease oxidation rates or changing the cladding material entirely to an alternate material (e.g., iron-based alloys or ceramic composites). All proposed ATF concepts require analysis to demonstrate that they maintain adequate performance during normal operation and anticipated transients (anticipated operational occurrences and design basis accidents) while achieving worthwhile performance improvements in severe accident scenarios [4].

Silicon carbide (SiC)-based ceramic composite cladding is an ATF cladding concept being researched at Oak Ridge National Laboratory (ORNL) and elsewhere. This work focuses specifically on thermomechanical fuel behavior and performance aspects of fully ceramic $\mathrm{SiC} / \mathrm{SiC}$ fiber/matrix composite cladding as an alternate cladding material in pressurized water reactors (PWRs). Modeling and simulation efforts in this study focus on using the BISON code developed at the Idaho National Laboratory (INL) to simulate SIC PWR cladding including testing some basis approaches to modeling the material properties of $\mathrm{SiC}$ composite cladding tubes. These are early efforts intended to demonstrate key capabilities in establishing SiC models in BISON including material model functionality and code use for duplex composite cladding tubes. Future work should expand on these efforts by (1) developing more sophisticated, more accurate material models, (2) updating the material models in BISON as more knowledge of $\mathrm{SiC}$ composites becomes available through experimental testing efforts, and (3) using engineering-scale simulations to assess the behavior and expected performance for a variety of different possible SiC-based composite cladding designs that may vary geometry, materials, or the number and/or arrangement of layers in the tube. This work should also be extended to the assessment of BWR fuel cladding and channel boxes.

This report serves as the deliverable fulfilling milestone number M2FT-15OR0202331 within Work Package FY15-15OR0202233 at ORNL for the DOE-NE Advanced Fuels Campaign. 


\section{BACKGROUND}

SiC-based ceramic matrix composites (CMCs) [5-8] are being developed and evaluated internationally as potential LWR cladding options. These development activities include interests within both the DOE-NE LWR Sustainability (LWRS) Program and the DOE-NE Advanced Fuels Campaign. The LWRS Program considers $\mathrm{SiC}$ ceramic matrix composites (CMCs) as offering potentially revolutionary gains as a cladding material, with possible benefits including more efficient normal operating conditions and higher safety margins under accident conditions [9]. Within the Advanced Fuels Campaign, SiC-based composites are a candidate ATF cladding material that could achieve several goals, such as reducing the rates of heat and hydrogen generation due to lower cladding oxidation rates in HT steam [10]. This work focuses on the application of SiC cladding as an ATF cladding material in PWRs, but these work efforts also support the general development and assessment of $\mathrm{SiC}$ as an LWR cladding material in a much broader sense.

\subsection{SILICON CARBIDE DEVELOPMENT PROGRAM}

$\mathrm{SiC}$ fiber/SiC matrix ceramic composites ( $\mathrm{SiC} / \mathrm{SiC}$ composites) are attractive nuclear structural materials due to their exceptional HT capability, radiation tolerance, neutron transparency, and availability as specialty industrial materials. Given that there is no degradation of strength up to at least $1400^{\circ} \mathrm{C}$ and very low HT steam oxidation rates, $\mathrm{SiC} / \mathrm{SiC}$ composites are among the leading candidates to replace Zircaloy as accident-tolerant LWR fuel and core constituents. However, the viability of $\mathrm{SiC} / \mathrm{SiC}$ composites as LWR fuel cladding or core components requires the consideration of numerous development and feasibility issues. One such issue is whether $\mathrm{SiC} / \mathrm{SiC}$ composite cladding can retain fission products. This requires demonstrating joining techniques that do not degrade due to service conditions (e.g., neutron and gamma particle radiation fields, appropriate temperatures, and coolant LWR chemistry environments) and limiting micro-cracking, which has a high statistical probability of occurring in these brittle materials at relatively low levels of stress [11]. Detailed thermomechanical models that account for the temperatureand irradiation-dependent behavior of $\mathrm{SiC} / \mathrm{SiC}$ composites are needed to estimate the stress distributions in these structures, with specific attention paid to the significant phenomenological and behavioral evolution differences between $\mathrm{SiC} / \mathrm{SiC}$ composites and metallic materials such as Zircaloy. The resulting stress and strain distributions can be used to estimate failure probabilities in these structures. Another important area to consider is the hydrothermal corrosion of SiC-based materials in high-temperature and high-pressure water. $\mathrm{SiC}$ forms silica under these conditions, which subsequently dissolves into the coolant water; this $\mathrm{SiC}$ corrosion rate varies based on coolant chemistry conditions and increases during irradiation. Finally, due to most historical $\mathrm{SiC}$ data coming from neutron irradiation experiments conducted at higher temperatures, an effort must be undertaken to examine low temperature $\left(200-400{ }^{\circ} \mathrm{C}\right)$ irradiation effects as total radiation damage levels appropriate for expected service conditions in LWRs. This paper reports the latest results in the areas identified above and sets the direction for future focused research towards viable application of $\mathrm{SiC} / \mathrm{SiC} \mathrm{CMCs}$ as LWR fuel cladding or core components.

Multiple potential applications invite a broad interest in SiC composites that has led to a Systematic Technology Evaluation Program (STEP) for LWR SiC/SiC composite cladding. This STEP plan frames a strong materials technology development program focused on addressing critical feasibility issues and advancing the technology readiness levels of key aspects of SiC cladding [12]. A plethora of SiC composite cladding design concepts have been proposed, and some have been partially tested or analyzed [13-16], but no single generally accepted reference design candidate exists for this class of cladding material; therefore, systems analysis efforts examining both PWRs [17] and boiling water reactors (BWRs) [18] have focused on high-level assessments of SiC-based cladding using smeared properties (e.g., density) that more than suffice for neutronic analyses. While demonstrating that $\mathrm{SiC} / \mathrm{SiC}$ composite cladding concepts may achieve promising neutronics performance, these studies also identified fuel 
reliability as a potential challenge [19]. Section 2.2 summarizes the neutronic assessment of $\mathrm{SiC} / \mathrm{SiC}$ composites as a candidate PWR cladding material.

This work aids assessment of the predicted thermomechanical fuel performance of SiC composite cladding in PWRs by establishing properly functioning material models for $\mathrm{SiC}$ using the best material property data available, with a focus on LWR-relevant irradiation conditions (e.g., temperatures) and demonstrating their use in the simple thermomechanical fuel performance calculations performed. This work also helps establish a foundation for future assessment of candidate LWR SiC composite cladding designs using both realistic and conservative assumptions for irradiation conditions such as power histories and operating temperatures.

\subsection{NEUTRONIC ASSESSMENT OF SILICON CARBIDE FOR PWR CLADDING}

Early neutronics analyses of PWR ATF cladding concepts $[17,19]$ included a SiC cladding material based on a generic $\mathrm{SiC} / \mathrm{SiC}$ composite that represents a range of concepts investigated for use in LWRs $[14,20,21]$. They also included a generic ferritic iron-chromium-aluminum (FeCrAl) alloy, which is another candidate ATF cladding material, as well as Zircaloy and historic 304SS cladding materials as reference points for comparisons. The reference case geometry for these analyses was based on a Westinghouse $17 \times 17$ PWR fuel rod. This section (Section 2.2) summarizes results from these previous efforts and cites them appropriately; no new work was performed.

The $\mathrm{SiC}$ and $\mathrm{FeCrAl}$ materials offer several advantages relative to using Zircaloy in an LWR including significantly slower oxidation kinetics in HT steam $[3,22,23,10]$ and superior HT strength for the metallic candidates. However, their use in LWRs also introduces several challenges in that FeCrAl absorbs more neutrons than Zircaloy when maintaining the same thickness, and SiC composites may require increased cladding thicknesses that would both increase neutron absorption and displace fuel loading volume. The low thermal conductivity in $\mathrm{SiC}$ also leads to elevated fuel temperatures [6, 24], as well as a large temperature gradient across the cladding that in turn induces large thermal stresses across the cladding thickness [13]. Table 1 summarizes several important parameters for Zircaloy, FeCrAl, and SiC including elemental composition, density, and macroscopic thermal neutron absorption cross section $\left(\Sigma_{\text {abs }}^{\text {therm }}\right)$ taken at a neutron energy of $0.253 \mathrm{eV}$.

Table 1. Summary of relevant data for key cladding material options, adapted from [17]

\begin{tabular}{lccc}
\hline \multicolumn{1}{c}{ Clad material } & Density $\left(\mathbf{g} / \mathbf{c m}^{\mathbf{3}}\right)$ & Composition $(\mathbf{w t} \%)$ & $\boldsymbol{\Sigma}_{\mathbf{a b s}}^{\text {therm }}\left(\mathbf{c m}^{-\mathbf{1}}\right)$ \\
\hline Zircaloy & 6.56 & $98.26 \mathrm{Zr}, 1.49 \mathrm{Sn}, 0.15 \mathrm{Fe}, 0.1 \mathrm{Cr}$ & 0.0028 \\
$\mathrm{FeCrAl}$ & 7.1 & $75 \mathrm{Fe}, 20 \mathrm{Cr}, 5 \mathrm{Al}$ & 0.0634 \\
$\mathrm{SiC}$ & 2.58 & $70.08 \mathrm{Si}, 29.92 \mathrm{C}$ & 0.0021 \\
\hline
\end{tabular}

Depletion analyses determined combinations of cladding thickness and enrichment that would enable each clad material option to achieve the same cycle length as Zircaloy. If the cladding thickness were varied, a constant pellet-clad gap thickness was maintained by varying the fuel pellet diameter directly with the clad inner diameter change. Three specific cases of interest were considered for each candidate alternate clad material with regard to matching the Zircaloy cycle length [19]:

I. What cladding thickness would be required if the reference $4.9 \%$ enrichment were maintained? 
II. What enrichment would be required if the reference cladding thickness $(571.5 \mu \mathrm{m})$ were maintained?

III. What enrichment would be required if the clad thickness were set to a reasonably conservative value $(350 \mu \mathrm{m}$ for iron-based alloys, $\sim 900 \mu \mathrm{m}$ for $\mathrm{SiC})$ ?

The resulting cladding thickness and enrichment combinations for each case are summarized in Table 2 and illustrated in Fig. 1. Combinations of enrichment and clad thickness are to the left and upward of the linear trend line shown for each material in Fig. 1 that is expected to meet or exceed the PWR cycle length requirements [17,19]. Reduced neutron absorption in SiC cladding enabled an enrichment of less than $4.9 \%$ to match the Zircaloy cycle length with the reference clad thickness (Case II), but increased $\mathrm{SiC}$ cladding thicknesses (Case III) would require enrichment increases due to decreased fuel pellet diameters. All of these results are based primarily on neutronic performance. Some simple and high-level thermomechanical fuel performance considerations helped establish rough guidelines for minimum $\mathrm{FeCrAl}$ thickness and possible $\mathrm{SiC}$ thicknesses needed, but explicit thermomechanical fuel performance analyses are needed to show whether these cases would likely achieve failure probabilities low enough for commercial applications.

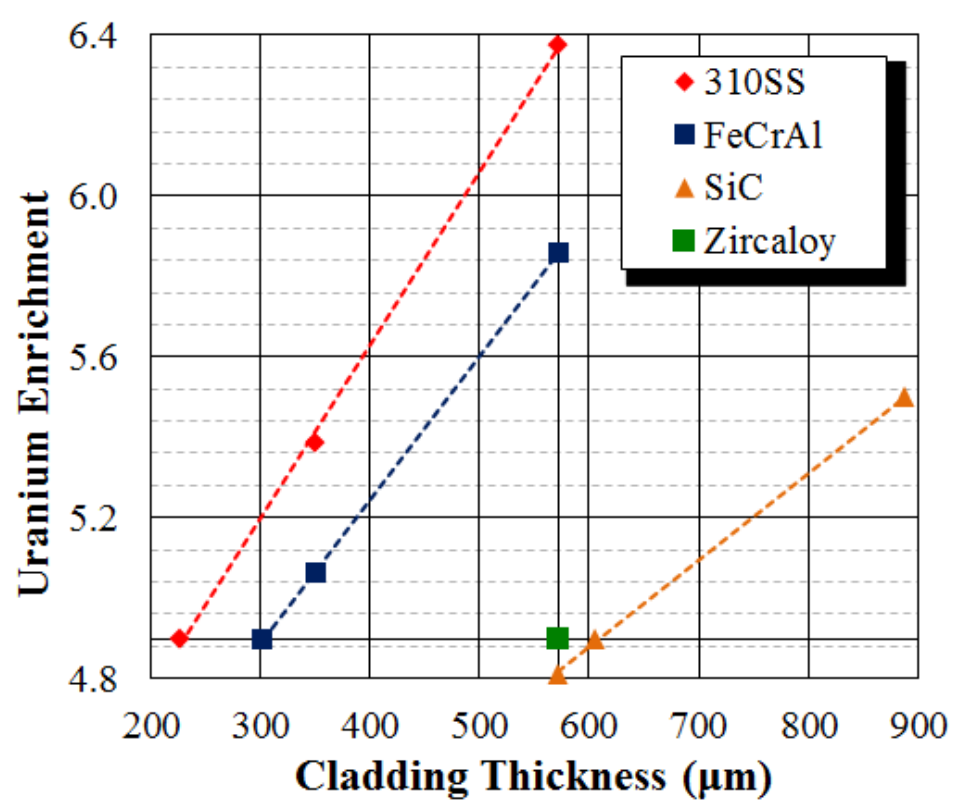

Fig. 1. Fuel parameter combinations that match cycle length of PWR with Zircaloy. [17,19]

Table 2. Fuel parameter combinations that match cycle length of PWR with Zircaloy [19]

\begin{tabular}{lcccccc}
\hline & \multicolumn{2}{c}{ Case I } & \multicolumn{2}{c}{ Case II } & \multicolumn{2}{c}{ Case III } \\
\cline { 2 - 7 } \multicolumn{1}{c}{ Material } & $\begin{array}{c}\text { Clad } \\
\text { thickness } \\
(\boldsymbol{\mu m})\end{array}$ & $\begin{array}{c}\text { Uranium } \\
\text { enrichment } \\
(\%)\end{array}$ & $\begin{array}{c}\text { Clad } \\
\text { thickness } \\
(\boldsymbol{\mu m})\end{array}$ & $\begin{array}{c}\text { Uranium } \\
\text { enrichment } \\
(\mathbf{\%})\end{array}$ & $\begin{array}{c}\text { Clad } \\
\text { thickness } \\
(\boldsymbol{\mu m})\end{array}$ & $\begin{array}{c}\text { Uranium } \\
\text { enrichment } \\
(\boldsymbol{\%})\end{array}$ \\
\hline Zircaloy & 571.5 & 4.9 & 571.5 & 4.9 & 571.5 & 4.9 \\
FeCrAl & 302.2 & 4.9 & 571.5 & 5.86 & 350 & 5.06 \\
$\mathrm{SiC}$ & 606.7 & 4.9 & 571.5 & 4.81 & 889 & 5.5 \\
\hline
\end{tabular}


Table 3 summarizes the data slightly differently for the reference Zircaloy case, as well as Case III for $\mathrm{FeCrAl}$ and Case II for $\mathrm{SiC}$. In addition to reporting the enrichment and cladding thickness combinations that matched the standard $\mathrm{UO}_{2} /$ Zircaloy cycle length, it also provides the specific power used in each case and the resulting discharge burnup after 1500 effective full power days (EFPD). The data in this table illustrate that the increased heavy metal (HM) loading in the FeCrAl case due to thinning the clad led to a lower specific power demand on the fuel, which correspondingly resulted in lower discharge burnup when operating for the same fuel endurance lifetime (1500 EFPD).

Table 3. Fuel specifications for ORNL PWR ATF analyses

\begin{tabular}{lccc}
\hline Parameter & $\begin{array}{c}\mathbf{U O}_{2} \\
\text { / Zircaloy }\end{array}$ & $\begin{array}{c}\mathbf{U O}_{2} \\
\text { / FeCrAl }\end{array}$ & $\begin{array}{c}\mathbf{U O}_{2} \\
\text { / SiC }\end{array}$ \\
\hline${ }^{235} \mathrm{U}$ enrichment & $4.9 \%$ & $5.06 \%$ & $4.9 \%$ \\
Cladding thickness $(\mu \mathrm{m})$ & 571.5 & 350 & 571.5 \\
Specific power $\left(\mathrm{MW} / \mathrm{tHM}^{\boldsymbol{a}}\right)$ & 38.33 & 34.49 & 38.33 \\
Fuel endurance $(\mathrm{EFPD})$ & 1500 & 1500 & 1500 \\
Discharge burnup $\left(\mathrm{GWd} / \mathrm{tHM}^{\boldsymbol{b}}\right)$ & 57.5 & 51.7 & 57.9 \\
\hline${ }^{\boldsymbol{a}} \mathrm{MW} / \mathrm{tHM}=$ megawatts per ton of heavy metal & & \\
${ }^{\boldsymbol{b}} \mathrm{GWd} / \mathrm{tHM}=$ gigawatt days per ton of heavy metal & &
\end{tabular}

This neutronics assessment of candidate PWR ATF cladding materials indicates that SiC performed well using the standard Zircaloy thickness, but large increases in clad thickness would have negative impacts on reactivity and fuel temperatures. The assessment also showed that all of the ATF concepts discussed require further analysis including stand-alone and coupled thermomechanical fuel performance analysis. Further details of the neutronics assessment may be found in the original documents $[17,19]$. 


\section{METHODS AND MODELS}

The primary purpose of this work was to develop and demonstrate some early implementations of SiC material models and fuel pin models for PWR SiC composite cladding. This current effort is therefore primarily focused on early development activities and an initial benchmarking exercise. Simple models are used in order to demonstrate proper functionality of material models and to establish confidence in both the code and the user by proving that calculations for $\mathrm{SiC}$ composite cladding produce wellunderstood, reasonable answers. Once this foundation has been established, future work and parallel efforts can further develop more detailed material models, analyze specific design concepts of interest, and assess the impacts of various uncertainties or design changes on the predicted behavior and performance of $\mathrm{SiC}$ composite cladding.

Thermomechanical fuel performance calculations in this work used the BISON fuel performance code $[25,26]$ developed by Idaho National Laboratory (INL). Efforts that occurred in the recent past [13] or that are ongoing have made headway in modeling SiC composite LWR cladding. Some efforts even include specific work modeling SiC cladding with BISON. However, the BISON input files and material models that are included in the publicly available BISON build do not support extensive modeling of SiC, and any improved models that may have been produced by specific organizations for their use were not available for this current work. This current work therefore requires a new BISON model and material model development.

The models created and run during this work will largely fall into two categories: (1) a simplified benchmark problem to test BISON, improve familiarity with it, and perform material property investigations; and (2) candidate $\mathrm{SiC}$ composite cladding design models used to aid in guiding design decisions for SiC cladding.

\subsection{THERMOMECHANICAL FUEL PERFORMANCE MODELING}

The BISON code uses a finite element approach built on the Multiphysics Object-Oriented Software Environment (MOOSE) framework [27], which is intended to enable seamless multiscale, coupled multiphysics simulations modeling two-dimensional (2D) or three-dimensional (3D) problems.

The MOOSE framework is a finite element based framework designed to enable massively parallel multiphysics calculations by solving systems of coupled nonlinear partial differential equations (PDEs) using a Jacobian-Free Newton Krylov (JFNK) approach [25,26]. Built upon existing libraries such as PETSc and libMesh, MOOSE provides an object-oriented framework intended to minimize the development time and effort of applications such as BISON or specific modules embedded within the applications that are built on top of MOOSE. In addition, MOOSE provides support for complex, unstructured, finite element meshes of various dimensions (1D, 2D, or 3D) using numerous types of element shapes (e.g., QUAD or HEX) and shape functions.

BISON is an application written within the MOOSE framework as a fuel behavior code designed to be a general tool for 2D axisymmetric or 3D numerical simulations of nuclear fuel performance for various types of fuels and problems. BISON's governing equations consist of a set of fully coupled PDEs that enforce the simultaneous conservation of energy, momentum, and species. Conservation of energy uses the heat conduction equation, conservation of momentum follows Cauchy's equation, and conservation of species combines several equations including Fick's law for mass flux and time-dependent species concentration equations that account for both sinks (e.g., radioactive decay) and sources [26]. 
Early BISON development work, demonstration of its capabilities through verification and validation efforts, and application of the BISON code to problems of interest have all mostly focused on $\mathrm{UO}_{2} /$ Zircaloy LWR fuels. Material models exist in BISON for $\mathrm{UO}_{2}$ fuel and Zircaloy cladding [25]. Some development efforts and application studies have also applied BISON to a variety of other nuclear fuel systems of interest including advanced LWR fuel and cladding materials, particle-based fuels, research reactor fuels, and metallic fuels being developed for possible future fast reactors [26]. The application of BISON to advanced LWR fuels provides a starting place for modeling SiC cladding, though many of the material models and input file modeling approaches needed for $\mathrm{SiC}$ composite cladding do not exist in the publicly available BISON repository and must therefore be developed and tested.

Initial assessments of using BISON for LWR fuel performance modeling may be found in the literature, including verification and validation work comparing BISON results to other codes and experimental data [28], as well as a closer look at how the capabilities and features of BISON handle practical applications within LWR fuel performance analysis [29]. Further details of the features, capabilities, and use of BISON may be found in the BISON Theory Manual [25] and the BISON Users' Manual [30].

\subsection{MATERIAL MODELS}

A multitude of different material property correlations and values must be provided for thermomechanical fuel performance calculations including items related to heat transfer (e.g., thermal conductivity), elastic behavior (e.g., Young's modulus), and irradiation-induced effects (e.g., volumetric swelling). Many of these correlations or values contain functional dependencies (e.g., varying with temperature, density, or irradiation damage) and they also may vary strongly between $\mathrm{SiC}$ materials fabricated using different processes. Properties for pure monolithic SiC produced via chemical vapor deposition (CVD SiC) are well established in the literature [24,31]. More recent work has also documented experimental data for the material properties of $\mathrm{SiC}$ produced through nanoinfiltration and transient eutectic-phase (NITE) processing (NITE SiC) [13,32], chemical vapor infiltration (CVI) SiC (CVI SiC) [6], and composites encasing $\mathrm{SiC}$ fibers $\left(\mathrm{SiC}_{\mathrm{f}}\right)$ in a CVI SiC matrix $\left(\mathrm{SiC}_{\mathrm{m}}\right)[5,6]$.

The standard version of BISON only contains a creep model specifically developed for CVD SiC; other properties of $\mathrm{SiC}$ must be modeled using general BISON material models or by developing new material models. This work used some of the general material models for simplified SiC material correlations and properties but then also developed new material models specific to various forms of SiC, especially CVD $\mathrm{SiC}$ and composite $\mathrm{SiC}$. 


\section{SILICON CARBIDE BENCHMARK PROBLEM SPECIFICATION}

The BISON material model development, input file development, and mesh generation efforts covered in this report focus on a relatively simple benchmark problem was developed in 2014 to allow code-to-code comparisons of predictions for SiC-based composite cladding as part of a workshop on SiC modeling techniques [33]. While the full specifications of this benchmark do not appear to be publicly available at this point, a basic description of the benchmark problem is available and is summarized herein.

This benchmark problem contains a short 2D (R-Z) length of duplex SiC cladding (inner monolith, outer composite $\mathrm{SiC}_{\mathrm{f}} / \mathrm{SiC}_{\mathrm{m}}$ ) without any fuel pellets in it. The problem only examines a steady-state condition, without any time dependence. The combination of using a cladding tube without fuel and steady-state conditions allows the problem to constrain many potential complications and code differences and focus in on narrow issues related to tightly specified SiC cladding behaviors. A visual summary of the geometry and boundary conditions of the benchmark problem are provided in Fig. 2.

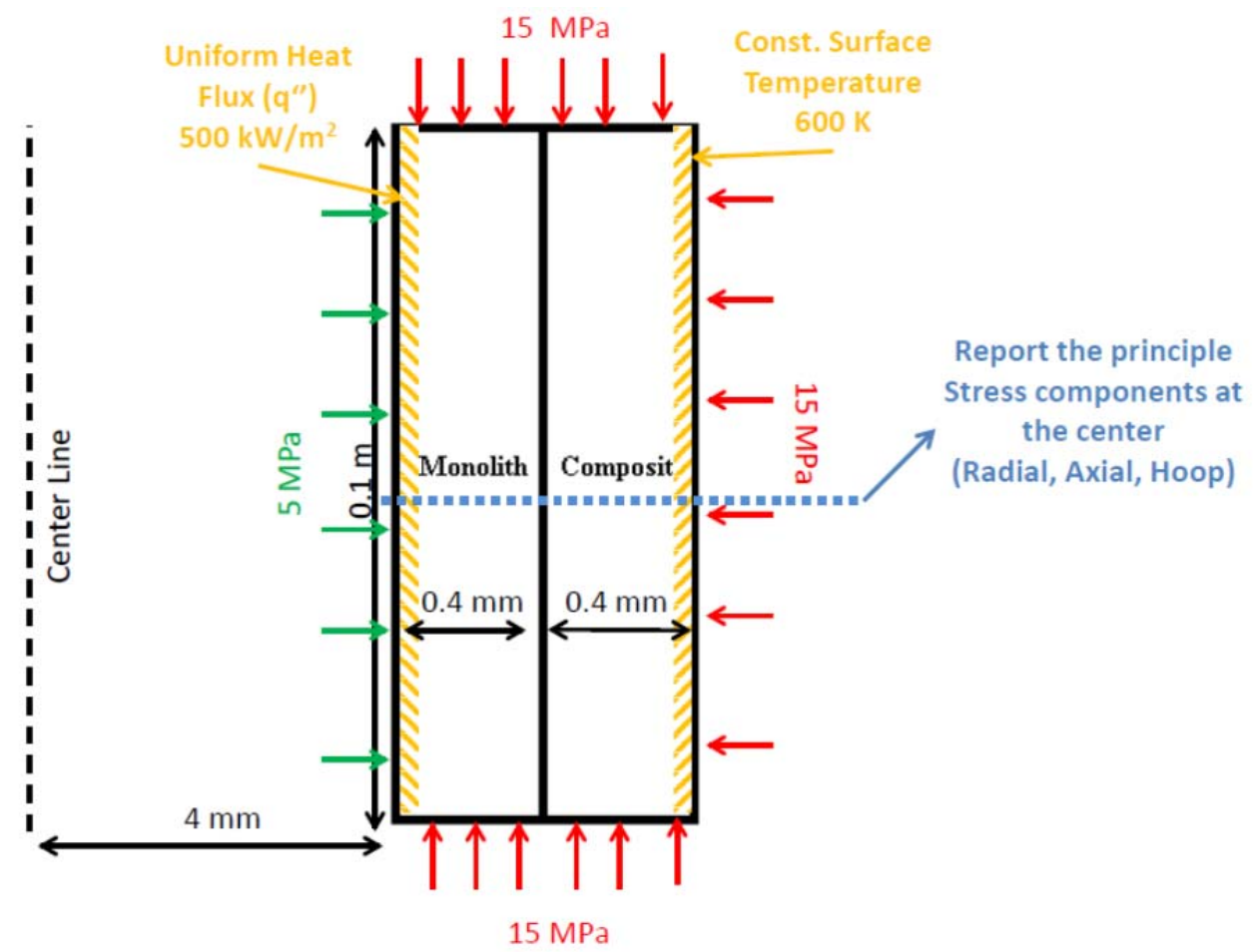

Fig. 2. Illustration summarizing the SiC benchmark problem geometry and specifications [33]. 


\section{RESULTS}

The BISON models developed of the SiC benchmark problem as part of this work effort used CUBIT to generate a mesh specific to the problem at hand. Temperature, heat flux, and pressure boundary conditions were clearly specified for the problem and were therefore applied in BISON. A 2-D R-Z model of the problem was developed and is shown in Fig. 3 was used. A square mesh was applied to both SiC cladding layers with the elements sized to divide each cladding layer into 10 radial intervals.

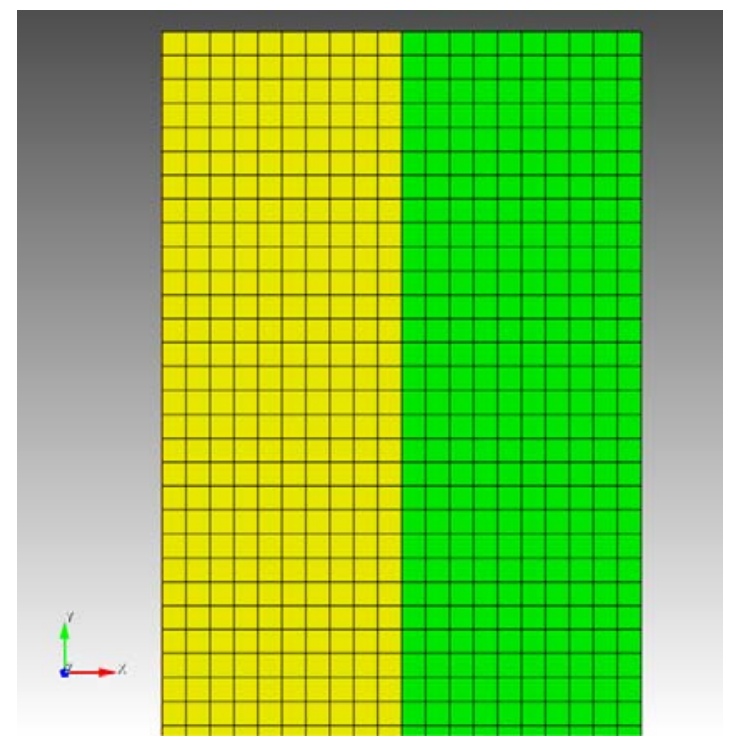

Fig. 3. Close-up view of the top of the 2D model for the SiC benchmark problem.

Initial calculations were performed using simplified $\mathrm{SiC}$ material property models and values specified for the benchmark problem. The radial, axial, and hoop stress profiles taken across the cladding thickness at the axial midplane of the tube section were extracted from the output data and are shown Fig. 4 . These results demonstrate close agreement with results from other codes used to complete the same benchmark calculations, thus showing that the BISON model implementation is functioning properly. Radial stress results around the axial midplane are shown in Fig. 5, with peak compressive stress values around -24 $\mathrm{MPa}$. These calculates are at a single point in time and do not have any time-dependence.
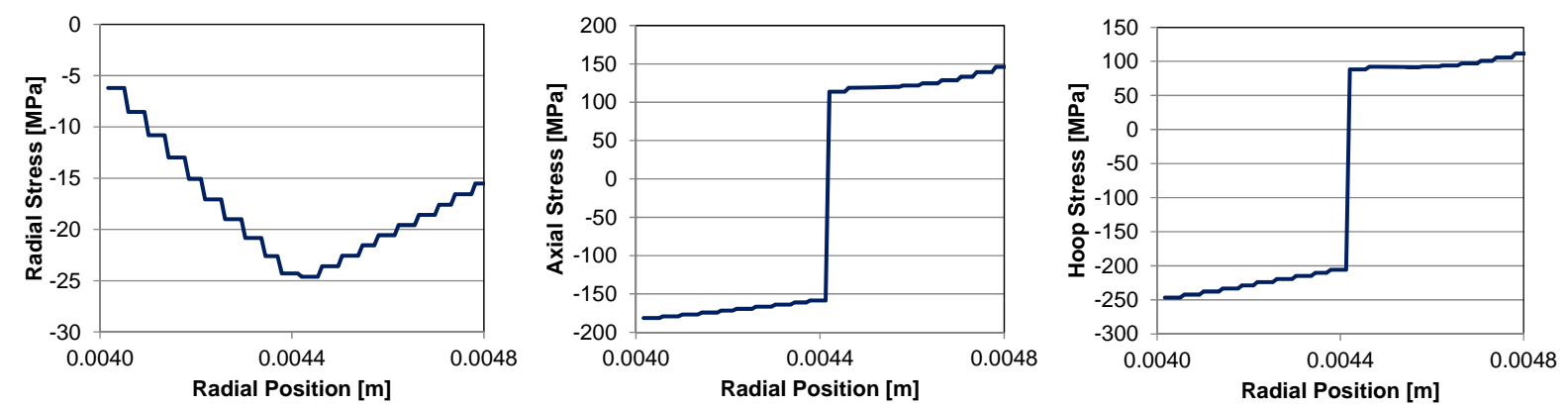

Fig. 4. Radial (left), axial (center), and hoop (right) stress profiles calculated across the cladding tube at the axial midplane of the benchmark problem using simplified material properties. 


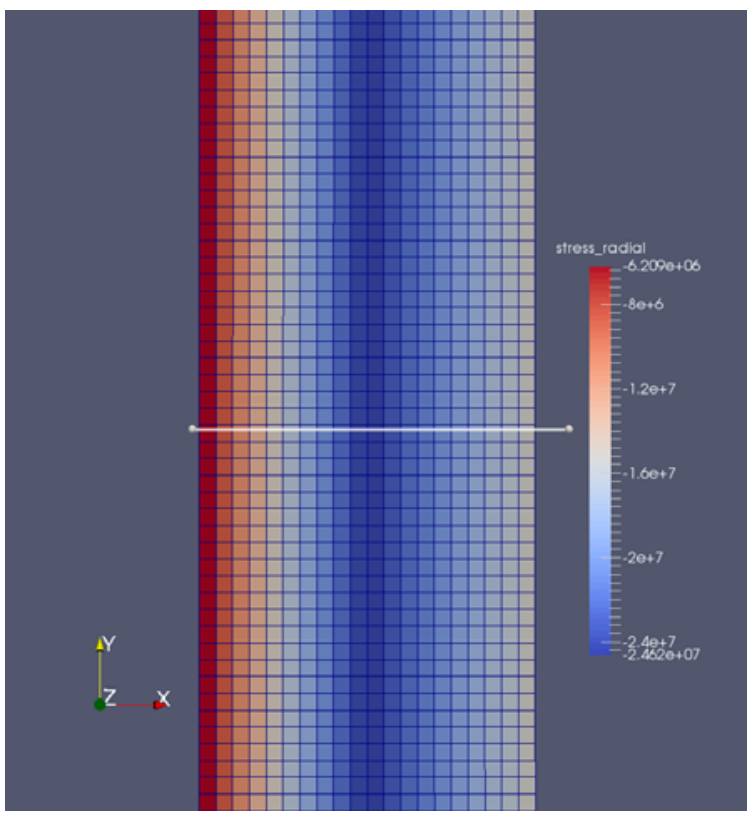

Fig. 5. Radial stress results near the axial midplane (marked with a white line) of the SiC cladding benchmark using simplified material properties.

Calculations were also performed using the same benchmark problem geometry and boundary conditions but with updated material models (e.g., thermal conductivity) containing more detail and better fidelity. However, most material models remained unchanged, because this benchmark problem was for steadystate without irradiation and therefore dose/damage-dependent material models were not of any practical use. Results from these calculations with the limited updated models are not shown and in some cases were not even fully extracted from output data because initial results clearly indicated little if any difference between the updated models and the simpler ones for this benchmark problem due to its simplistic nature.

For general use in $\mathrm{SiC}$ fuel modeling in BISON, updated material models should be developed using the best data and fits available in the literature. Damage-dependent material models which are being implemented into BISON via parallel efforts at ORNL will offer improved fidelity and new dependencies (e.g., radiation damage and 3D effects) and should be continually updated as new data become available from ongoing experimental testing efforts. 


\section{CONCLUSIONS}

Preliminary thermomechanical fuel performance models for SiC-based composite cladding have been created in the BISON fuel performance code. Initial calculations using a computational benchmark problem with simplified material properties demonstrated that the calculations in this current work matched the results from other fuel performance codes and users. This provides some early confidence that material models and input development should prove successful within BISON as ongoing work develops more complicated models and examines problems more representative of SiC LWR cladding.

Future work in this area will include continual improvement of the monolithic and composite SiC material property models being used in BISON, as well as assessments of candidate SiC-based composite LWR cladding designs. These assessments could investigate specific concepts with very detailed geometry and material definitions; however, some of their best value will likely be found in analyzing much broader design decisions such as duplex versus triplex cladding designs, comparing fully ceramic composite designs with ceramic-metallic designs, trying to optimize specific layer thicknesses, or even trying to help guide technology development efforts by identifying optimal material properties or features of the different layers that improve overall fuel performance. They could also be used to explore the sensitivity of SiC cladding performance to existing uncertainties in material properties to help prioritize what experimental research activities would have the highest impact, which could be especially beneficial to the $\mathrm{SiC}$ technology development program in today's reality of budget constraints and multiple parallel research priorities. 


\section{ACKNOWLEDGEMENTS}

The author gratefully acknowledges key insights and contributions on this work from Kurt Terrani, Yutai Katoh, and Lance Snead in the areas of SiC material properties, modeling, and overall feedback. Steve Novascone, a member of the BISON development team at INL, was extremely responsive and helpful in answering questions about BISON input syntax and sharing best practices for mitigating or solving some of the challenges encountered along the way. Nathan Capps also provided useful feedback and help with input syntax for running BISON, along with help on how to post-process desired information. Several people provided essential help in getting BISON properly configured on ORNL machines including Mark Baird, Kevin Clarno, and Roger Pawlowski. Rose Montgomery helped answer several questions regarding geometry and mesh generation when using CUBIT. Kevin Clarno and Yutai Katoh provided useful feedback and comments on draft versions of this report that significantly improved its quality and usefulness. This work was funded by the Advanced Fuels Campaign, which is part of the Fuel Cycle Research and Development program within the US DOE Office of Nuclear Energy. 


\section{REFERENCES}

1. W. J. Carmack, F. Goldner, S. M. Bragg-Sitton, and L. L. Snead, "Overview of the U.S. DOE accident tolerant fuel development program," Proc. 2013 LWR Fuel Performance Meeting/TopFuel 2013, Charlotte, North Carolina, USA, September 15-19, 2013, American Nuclear Society (2013) 734-739.

2. S. J. Zinkle, K. A. Terrani, J. C. Gehin, L. J. Ott, and L. L. Snead, “Accident tolerant fuels for LWRs: A perspective," J Nucl Mater, no. 448 (2014) 374-379.

3. K. A. Terrani, S. J. Zinkle, and L .L. Snead, "Advanced oxidation-resistant iron-based alloys for LWR fuel cladding," J Nucl Mater, no. 448 (2014) 420-435.

4. S. Bragg-Sitton et al., "Light Water Reactor Accident Tolerant Fuel Performance Metrics," FCRDFUEL-2013-000264, Idaho National Laboratory, ID (2014).

5. R. Naslain, "Design, preparation and properties of non-oxide CMCs for application in engines and nuclear reactors: an overview," Composites Science and Technology, no. 64, 155-170 (2004).

6. Y. Katoh, K. Ozawa, C. Shih, T. Nozawa, R.J. Shinavski, A. Hasegawa, L.L. Snead, "Continuous SiC fiber, CVI SiC matrix composites for nuclear applications: Properties and irradiation effects," J Nucl Mater, no. 448 (2014) 448-476.

7. K. Yueh, K.A. Terrani, "Silicon carbide composite for light water reactor fuel assembly applications," J Nucl Mater, no. 448, 380-388 (2014).

8. Y. Katoh, L.L. Snead, C.H. Nozawa, T. Henager Jr., T. Hinoki, A. Ivekivoic, S. Novak, S.M. Gonzalez-deVicente, "Current status and recent research achievements in $\mathrm{SiC} / \mathrm{SiC}$ composites", Journal of Nuclear Materials, no. 455, 387-397 (2014).

9. S.M. Bragg-Sitton (ed.), Light Water Reactor Sustainability Program: Advanced LWR Nuclear Fuel Cladding System Development Technical Program Plan, INL/MIS-12-25696, Rev. 1, prepared by the Idaho National Laboratory for the US Department of Energy Office of Nuclear Energy, Idaho Falls, ID, USA, (2012).

10. K.A. Terrani, B.A. Pint, C.M. Parish, C.M. Silva, L.L. Snead, Y. Katoh, "Silicon carbide oxidation in steam up to $2 \mathrm{MPa}$," J. Am. Ceram. Soc., no. 978 (2014) 2331-2352.

11. Y. Katoh, K. Terrani, "Technology Evaluation Program for SiC/SiC Composite-based AccidentTolerant LWR Fuel Cladding and Core Structures," Proceedings of The 11th Pacific Rim Conference of Ceramic Societies (PACRIM 11), Jeju, South Korea, August 30 - September 4, 2015.

12. Y. Katoh, K.A. Terrani, L.L. Snead, Systematic technology evaluation program for SiC/SiC composite-based accident-tolerant LWR fuel cladding and core structures, ORNL/TM-2014/210, Revision 1, Oak Ridge National Laboratory, Oak Ridge, TN, USA, (2014).

13. M. Ben-Belgacem, V. Richet, K.A. Terrani, Y. Katoh, and L.L. Snead, "Thermo-mechanical analysis of LWR SiC/SiC composite cladding," J Nucl Mater, no. 447 (2014) 125-142.

14. D.M. Carpenter, An assessment of silicon carbide as a cladding material for light water reactors, Doctoral Thesis, Massachusetts Institute of Technology (2010).

15. D. Bloore, Reactor Physics Assessment of Thick Silicon Carbide Cladding PWR Fuels, Master's Thesis, Massachusetts Institute of Technology, July 2013.

16. EPRI, Falcon-Based Comparative Assessment of Prototype Zr-4 and SiC Fuel Rod, EPRI-1022907, Electric Power Research Institute, Palo Alto, CA, USA, (2011).

17. N. M. George, K. A. Terrani, J. J. Powers, A. Worrall, G. I. Maldonado, "Neutronic analysis of candidate accident-tolerant cladding concepts in pressurized water reactors," Ann Nucl Energy, no. 75 (2015) 703-712.

18. N.M. George, J.J. Powers, G.I. Maldonado, A. Worrall, K.A. Terrani, "Demonstration of a full-core reactivity equivalence for $\mathrm{FeCrAl}$ enhanced accident tolerant fuel in BWRs," Proceedings of Advances in Nuclear Fuel Management V (ANFM V), Hilton Head Island, SC, USA, March 29-April 1, 2015. American Nuclear Society (2015). 
19. J. J. Powers, N. M. George, A. Worrall, K. A. Terrani, and G. I. Maldonado, "Reactor physics assessment of alternate cladding materials,” Transactions of the 2014 Water Reactor Fuel Performance Meeting/Top Fuel/LWR Fuel Performance Meeting (WRFPM2014/TopFuel 2014), Sendai, Japan (September 14-17, 2014).

20. K. Yueh, D. Carpenter, and H. Feinroth, "Clad in clay," Nucl Eng Int, no. 55 (2010) 14-16.

21. K. Yueh, K. A. Terrani, "Silicon carbide composite for light water reactor fuel assembly applications," J Nucl Mater, no. 448 (2014) 380-388.

22. B. A. Pint et al., "High temperature oxidation of fuel cladding candidate materials in steam-hydrogen environments," J Nucl Mater, no. 440 (2013) 420-427.

23. J. V. Cathcart et al., "Zirconium Metal-Water Oxidation Kinetics IV. Reaction Rate Studies," ORNL/NUREG-17, Oak Ridge National Laboratory, TN (1977).

24. L. L. Snead et al., "Handbook of SiC properties for fuel performance modeling," J Nucl Mater, no. 371 (2007) 329-377.

25. J.D. Hales et al., BISON Theory Manual: The Equations Behind Nuclear Fuel Analysis (Bison Release 1.1), INL/EXT-13-29930 Rev. 1, Idaho National Laboratory, Idaho Falls, ID, USA, (2014).

26. R.L. Williamson, J.D. Hales, S.R. Novascone, M.R. Tonks, D.R. Gaston, C.J. Permann, D. Andrs, R.C. Martineau, "Multidimensional multiphysics simulation of nuclear fuel behavior," J Nucl Mater, no. 423 (2012) 149-163.

27. D. Gaston, C. Newman, G. Hansen, D. Lebrun-Grandié, "MOOSE: A parallel computational framework for coupled systems of nonlinear equations," Nucl Eng Des, no. 239, vol. 10, (2009) $1768-1778$.

28. D.M. Perez et al., Assessment of BISON: A Nuclear Fuel Performance Analysis Code (BISON Release 1.1), INL/MIS-13-30314 Rev. 1, Idaho National Laboratory, Idaho Falls, ID, USA, (2014).

29. K. Shirvan, "Assessment of BISON Fuel Performance Code and Its Application to Advanced Fuels," Proceedings of the 2014 International Congress on Advances in Nuclear Power Plants (ICAPP 2014), Charlotte, NC, USA, April 6-9, 2014. American Nuclear Society, pp. 2267-2278, (2014).

30. J.D. Hales et al., BISON Users Manual (BISON Release 1.1), INL/MIS-13-30307 Rev. 2, Idaho National Laboratory, Idaho Falls, ID, USA, (2014).

31. Y. Katoh, L.L. Snead, C.M. Parish, T. Hinoki, "Observation and Possible Mechanism of Irradiation Induced Creep in Ceramics," J Nucl Mater, no. 434 (2013) 141-151.

32. T. Koyanagi, K. Ozawa, T. Hinoki, K. Shimoda, Y. Katoh, "Effects of neutron irradiation on mechanical properties of silicon carbide composites fabricated by nano-infiltrated transient eutectic process," J Nucl Mater, no. 448 (2014) 478-486.

33. "2014 Workshop on SiC Modeling Techniques." MIT Center for Advanced Nuclear Energy Systems. Web. 20 August 2015. https://canes.mit.edu/symposia/2014/sic-modeling-techniques 
APPENDIX A. REPRESENTATIVE BISON INPUT FILE FOR THE SIC CLADDING BENCHMARK PROBLEM 



\section{APPENDIX A. REPRESENTATIVE BISON INPUT FILE FOR THE SIC CLADDING BENCHMARK PROBLEM}

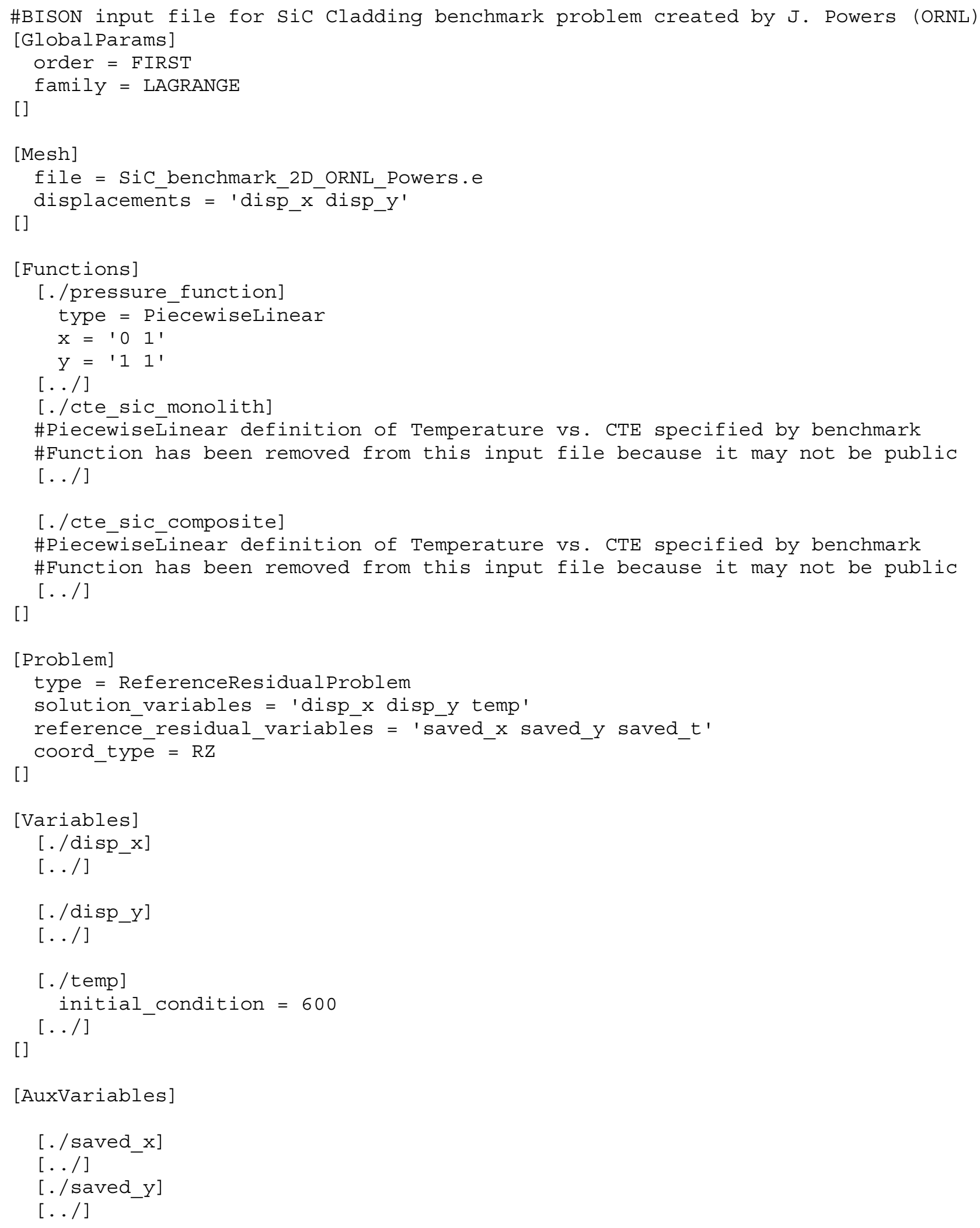




\begin{tabular}{|c|c|}
\hline 54 & [./saved_t] \\
\hline 55 & {$[\ldots /]$} \\
\hline 56 & \\
\hline 57 & [./stress_radial] \\
\hline 58 & order $=-$ CONSTANT \\
\hline 59 & family $=$ MONOMIAL \\
\hline 60 & {$[\ldots /]$} \\
\hline 61 & [./stress_axial] \\
\hline 62 & order = CONSTANT \\
\hline 63 & family $=$ MONOMIAL \\
\hline 64 & {$[\ldots /]$} \\
\hline 65 & [./stress_hoop] \\
\hline 66 & order $=$ CONSTANT \\
\hline 67 & family $=$ MONOMIAL \\
\hline 68 & {$[\ldots /]$} \\
\hline 69 & [./Vonmises] \\
\hline 70 & order = CONSTANT \\
\hline 71 & family $=$ MONOMIAL \\
\hline 72 & {$[\ldots /]$} \\
\hline 73 & [./strain axial] \\
\hline 74 & order $=$ CONSTANT \\
\hline 75 & family = MONOMIAL \\
\hline 76 & {$[\ldots /]$} \\
\hline 77 & [./strain hoop] \\
\hline 78 & order = CONSTANT \\
\hline 79 & family = MONOMIAL \\
\hline 80 & {$[\ldots /]$} \\
\hline 81 & [./strain radial] \\
\hline 82 & order $=$ CONSTANT \\
\hline 83 & family = MONOMIAL \\
\hline 84 & {$[\ldots /]$} \\
\hline 85 & \\
\hline 86 & [] \\
\hline 87 & \\
\hline 88 & [SolidMechanics] \\
\hline 89 & {$[. /$ solid $]$} \\
\hline 90 & disp_r $=$ disp_x \\
\hline 91 & disp_z $=$ disp_y \\
\hline 92 & temp $=$ temp \\
\hline 93 & save in disp $r=$ saved $x$ \\
\hline 94 & save in disp $z=$ saved $y$ \\
\hline 95 & {$[\ldots /]--1-1$} \\
\hline 96 & [] \\
\hline 97 & \\
\hline 98 & [Kernels] \\
\hline 99 & {$[. /$ heat $]$} \\
\hline 100 & type = HeatConduction \\
\hline 101 & variable = temp \\
\hline 102 & save in $=$ saved $t$ \\
\hline 103 & {$[\ldots /]-$} \\
\hline 104 & \\
\hline 105 & [ ] \\
\hline 106 & \\
\hline 107 & [AuxKernels] \\
\hline 108 & \\
\hline 109 & [./stress radial] \\
\hline 110 & type = MaterialTensorAux \\
\hline 111 & tensor = stress \\
\hline 112 & variable = stress radial \\
\hline
\end{tabular}




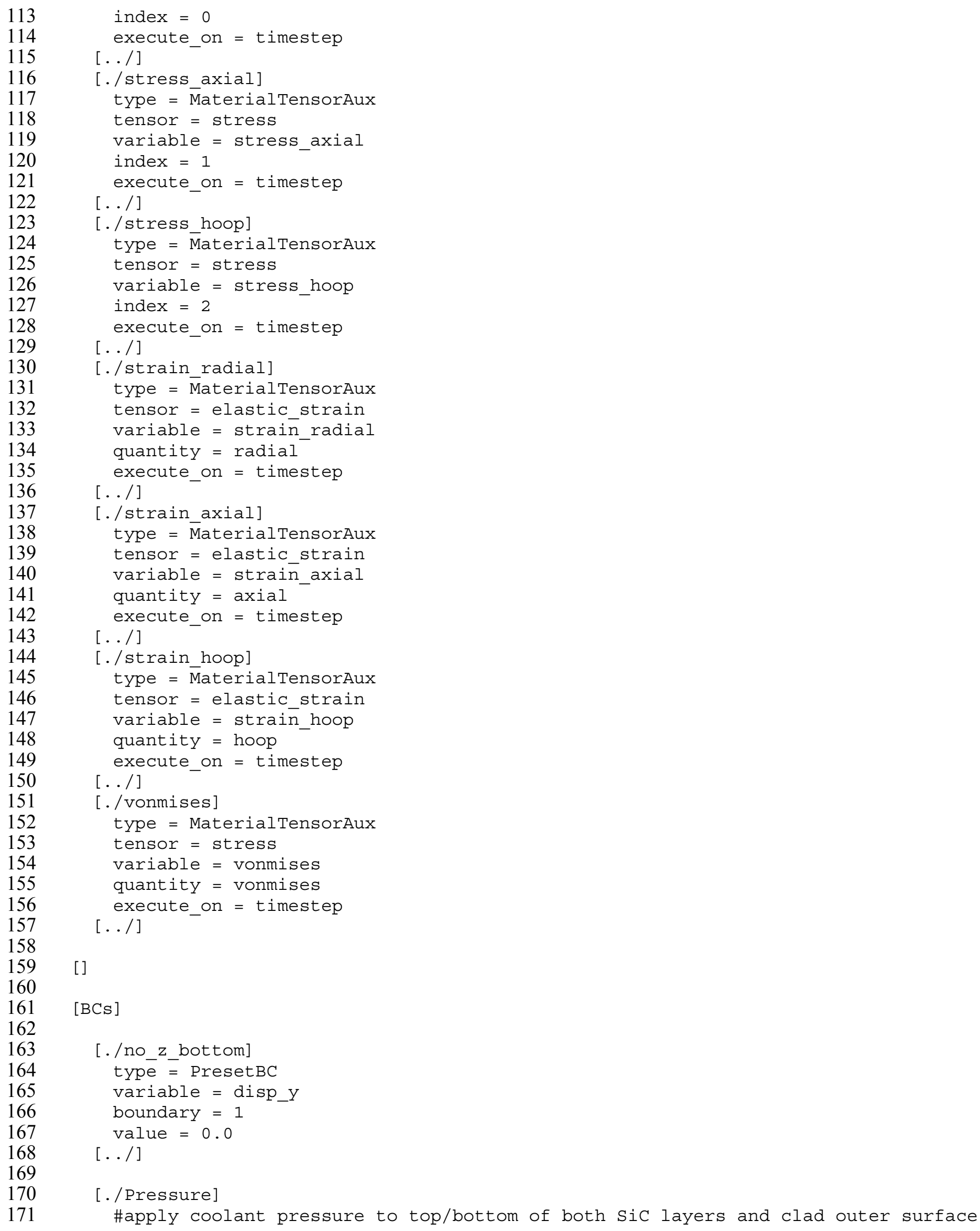

157

158

159 [ ]

160

$161 \quad[\mathrm{BCs}]$

162

163

164

165

166

167

168

169

170

171 
172

173

174

175

176

177

178

179

180

181

182

183

184

185

186

187

188

189

190

191

192

193

194

195

196

197

198

199

200

201

202

203

204

205

206

207

208

209

210

211

212

213

214

215

216

217

218

219

220

221

222

223

224

225

226

227

228

229

230

[./pressure1]

boundary $=1123$ '

factor $=1.50 e+07$

function = pressure_function

disp_x $=$ disp_x

disp_y $=$ disp_y

$[\ldots /]$

\#apply internal pin pressure (5 MPa) to inner surface of monolith layer

[./pressure2]

boundary $=5$

factor $=5.0 e+06$

function $=$ pressure_function

disp_x $=$ disp_x

disp_y $=$ disp_y

$[\ldots /]$

$[\ldots /]$

\#Establish BC for outer clad surface temperature of $600 \mathrm{~K}$

[. /OuterCladSurfaceTempBC]

type=DirichletBC

boundary $=2$

variable $=$ temp

value $=600$

$[\ldots /]$

\#Establish BC for inner clad surface heat flux of $500 \mathrm{~kW} / \mathrm{m}^{\wedge} 2$

[./HeatFluxBC]

type=NeumannBC

boundary $=5$

variable $=$ temp

value $=5.0 e+5$

$[\ldots /]$

[]

[Materials]

\#BISON input file for SiC Cladding benchmark problem created by J. Powers (ORNL) \# --- SiC MONOLITHIC LAYER ----

[./SiC_mono_disp]

type $=$ Elastic

block $=2$

disp_r $=$ disp_x

disp_z $=$ disp_y

temp $=$ temp

youngs_modulus = \# benchmark-specified value removed, may not be public poissons_ratio = \# benchmark-specified value removed, may not be public stress_free_temperature $=293$

thermaI_expansion_function = cte_sic_monolith

thermal_expansion_function_type $=$ mean

thermal_expansion_reference_temperature $=293$

$[\ldots /$ ]

[./SiC_mono_temp]

type $=$ HeatConductionMaterial

block $=2$

specific_heat = \# benchmark-specified value removed, may not be public

thermal_conductivity = \# benchmark-specified value removed, may not be public $[\ldots /]$

[./SiC_mono_dens] 
231

232

233

234

235

236

237

238

239

240

241

242

243

244

245

246

247

248

249

250

251

252

253

254

255

256

257

258

259

260

261

262

263

264

265

266

267

268

269

270

271

272

273

274

275

276

277

278

279

280

281

282

283

284

285

286

287

288

289

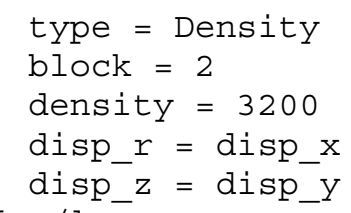


$[\ldots /]$

300

301

302

303

304

305

[./console] type $=$ Console perf_log = true output_linear $=$ true $[\ldots /]$

[] 